\title{
Acetabular Osteochondroma
}

Reynaldo Jesus Garcia ${ }^{1}$, Edmilson Takehiro Takata², Maria Teresa Seixas Alves ${ }^{3}$,

Osvaldo Guilherme Nunes Pires ${ }^{4}$, Ricardo Basili ${ }^{5}$

\section{SUMMARY:}

This is a case report of a patient with a intra-articular hip osteochondroma, an extremely rare location for this kind of lesion. The patient was treated with resection of the lesion and presen- ted a very good evolution with total recovery of the hip movements.

Keywords: Acetabulum; Osteochondroma; Femur head; Bone neoplasia; Hip.

\section{INTRODUCTION}

Osteochondromas are bone exosthosis covered by cartilage and are considered as benign tumors, behaving as latent or active. The ossification of the cartilage covering the exosthosis promotes it growth, leaving behind it the histologically normal bone.

Osteochondromas can affect all regions of the skeleton, being more common on tubular bones, scapula and iliac wing, and less frequent on carpus, tarsus, phalanges and vertebral bodies $^{(1,2,3)}$. Most of the cases they are extra-articular lesions. In long bones, they can be located at: the metaphyseal region (76\%); the metafisodiaphyseal region (16\%); and the diaphyseal region $(6 \%)^{(2)}$. They can be sessile or pediculated. They emerge as single or multiple hereditary osteochondromatosis.

Sometimes, the development of a reactive bursa occurs on the osteochondroma, as a consequence of the friction in adjacent structures, muscles and tendons. Although less frequently, an association may occur to such bursa, to the osteochondroma and to the synovial chondromatosis ${ }^{(4)}$.

Malignancy occurs in less than $1 \%$ of cases $^{(4)}$, usually to chondrosarcomas.

Among the differential diagnostics of osseous-cartilaginous exosthosis are included the chondrosarcoma, radiation-induced neoplasia(5) and the hemimelic epiphyseal displasia(6).

The purpose of this study is to report a case of acetabular osteochondroma, an extremely rare location for this kind of lesion.

\section{CLINICAL CASE}

A 13 year-old, white, female patient presenting with a complaint of pain lasting 11 months at right groin region. Pain was insidious, moderately strong and without irradiation. She also reported gradual limitation of the motion arch of right hip. At baseline physical examination, it was seen a restraining of flexion $\left(20-130^{\circ}\right)$, adduction $\left(0-5^{\circ}\right)$ and decreased inward rotation $\left(0-10^{\circ}\right)$ in such joint. She did not present with previous pathologies.

After baseline radiographies were performed, an intra-articular tumor of the right acetabulum (Figures 1A and 1B) was noted. On computed tomography, we saw an image compatible to intra-articular osteochondroma at the posteroinferior region of the acetabulum (Figure 2), as it was seen on magnetic nuclear resonance imaging (Figure 3).

Our treatment choice was lesion resection through a posterolateral access to the right hip, with acetabular posterior edge osteotomy. We removed the lesion with a 1-cm margin and fixed the osteotomy with a reconstruction plate and 4.5-cm screws.

The dried tumor (Figures 4 and 5) was sent to anatomicopathological examination (Figures 6 and 7), which confirmed the diagnosis of hip intra-articular osteochondroma.

Today, i.e., 2 years and 3 months after surgery, the patient is asymptomatic and presenting a normal motion arch. On radiograph (Figures 8 and 9) and on the computed tomography (control), after 2 years postoperatively, there is no sign of local recurrence of the tumor (Figure 10) 


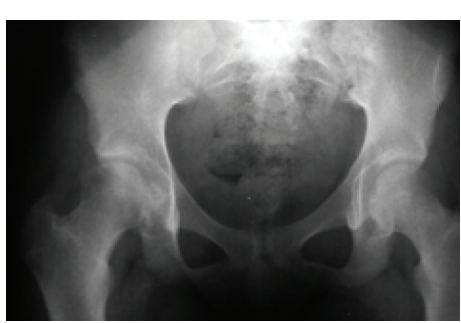

Figure 1A - Radiograph of the hips in an anteroposterior plane, where an intra-articular tumor is seen at the plane. right acetabulum.

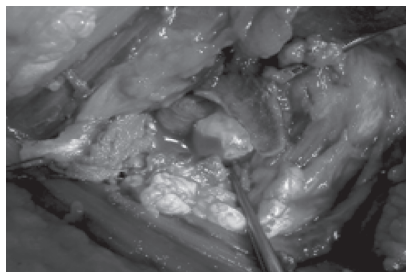

Figure 4 - Intraoperative photograph, showing osteotomy of the posterior acetabular edge and lesion.

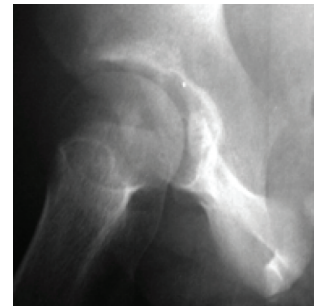

Figure 1B - Radiograph the right hip in a lateral

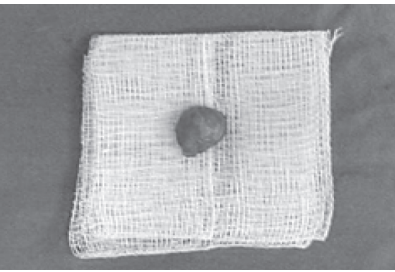

Figure 5 - Dried tumor.

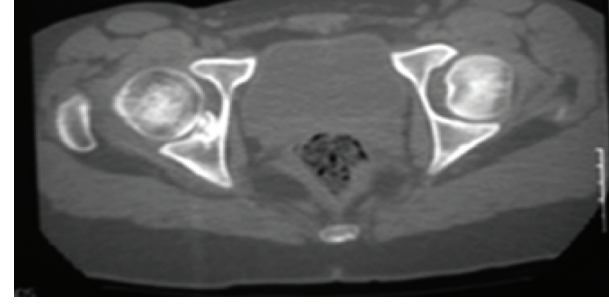

Figure 2 - Computed axial tomography, showing a tumor at the posteroinferior region of the acetabulum.

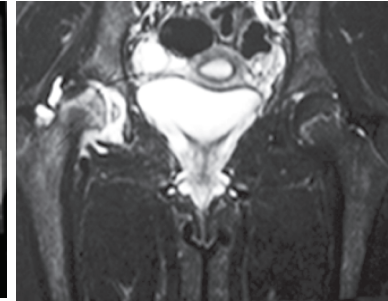

Figure 3 - Magnetic nuclear resonance in T2, with contrast stain injection, highlighting tumor and reactive synovitis.

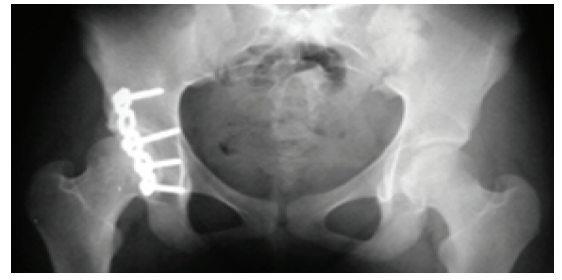

Figure 8 - Radiograph of the hips in an anteroposterior plane, two years postoperatively, evidencing no tumor recurrence.

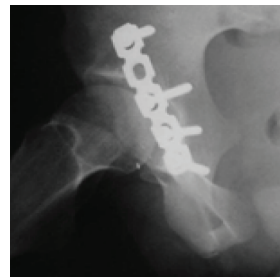

Figure 9 - Radiograph of the right hip in a lateral plane.

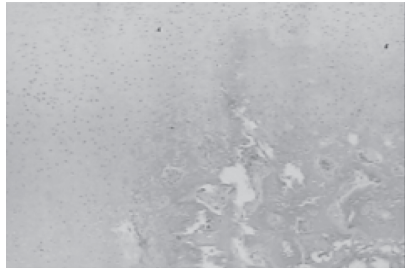

Figure 6 - Microphotograph H.E. 40X of the dried tumor. At the periphery, a cartilaginous coating is seen and an ossification zone is noted at the central portion with bone and typical spaces.

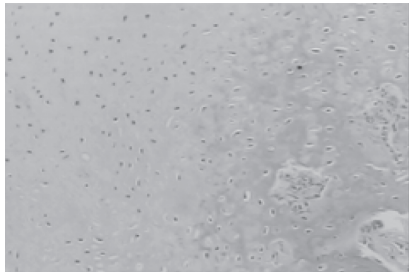

Figure 7 - Microphotograph H.E. 100X

Details of the cartilaginous coating and endochondral ossification zone.

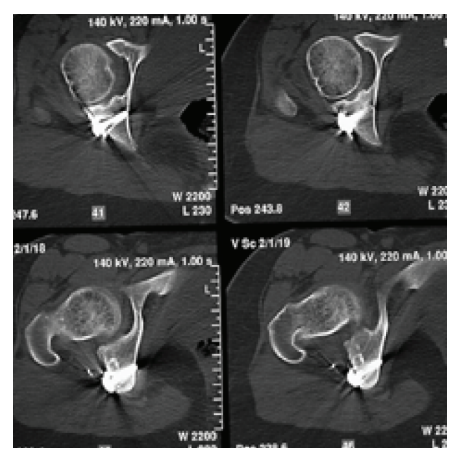

Figure 10 - Computed axial tomography, 2 years postoperatively, detailing the absence of local tumor recurrence.

\section{DISCUSSION}

Osteochondroma is a common bone tumor, but its intra-articular location is very rare. It has been described on the ankle ${ }^{(7,8)}$, on interphalangeal joints ${ }^{(2)}$, sacroiliac joint and femoral cervix ${ }^{(4,9,10)}$. In literature, we found reports of only two cases of osteochondroma with acetabular lesion in multiple hereditary exosthosis ${ }^{(11)}$ and just one case of single acetabular osteochondroma ${ }^{(6)}$.

They are symptomatic when they cause tendinous or muscular protuberances, joint blockage, neovascular structures pressure, fractures, or when they become malign ${ }^{(4)}$. In the case reported, in addition to the algesic condition and motion restrai- ning, which were much improved after surgery, there was - and still is - the risk of early osteoarthrosis of the operated hip.

For treatment, the thorough resection of the exosthosis and its cartilage layer is mandatory, as well as of the perichondrium covering it, because an incomplete resection of those structures can result in lesion recurrence.

In the patient reported, a thorough resection of the lesion was performed through a posterolateral access to the hip, with acetabular edge osteotomy, which provided a proper exposition to the lesion. Acetabulum perforation prior to osteotomy was preferred in order to facilitate its fixation by the end of surgery.

\section{REFERENCES}

1. Castillo M, Hudgins PA, Hoffman JC Jr. Lockjaw secondary to skull base osteochondroma: CT findings. Case report. J Comput Assist Tomogr 1989; 13:338-339.

2. Laflamme GY, Stanciu C. Ostéochondromes intra-articulaires isoles des phalanges chez les infants. Ann Chir 1998; 52 :791-794.

3. Paik NJ, Han TR, Lim SJ. Multiple peripheral nerve compressions related to malignantly transformed hereditary multiple exostose. Muscle Nerve 2000; 23: 1290-1294.

4. Peh WCG, Shek TW, Davies AM, Wong JW, Chien EP. Osteochondroma and secondary osteochondromatosis. Case report. Skeletal Radiol 1999; 28:169-174.

5. DeSimone DP, Abdelwahab IF, Kenan S, Klein MJ, Lewis MM. Case report 785: Radiation-induced osteochondroma of the ilium. Skeletal Radiol 1993; 22:289-291.

6. Bleshman MH, Levy RM. An unusual location of an osteochondroma. Case report. Radiology 1978; 127: 456.

7. Cohen AP, Giannoudis PV, Hinsche A, Smith RM, Matthews SJ. Post-traumatic giant intraarticular synovial osteochondroma of the knee. Case report. Injury 2001; 32:87-89.

8. Yamashita T, Sakamoto N, Ishikawa I, Usui M, Fujisawa Y. Intra-articular osteochondroma of the ankle joint. J Foot Ankle Surg 1998; 37:66-68.

9. Schumacher TM, Genant HK, Korobkin M, Bovill EG Jr. Computed tomography. Its use in space-occupying lesion of the musculoskeletal system. J Bone Joint Surg Am 1978; 60:600-607.218

10. Siebenrocky KA, Ganz R. Osteochondroma of the femoral neck. Clin Orthop 2002 393:211-218

11. Woodward MN, Daly KE, Dodds RD, Fixsen JA. Subluxation of the hip joint in multiple hereditary osteochondromatosis: report of two cases. J Pediatr Orthop 1999; 19:119-121. 